Available online at: https://journals.researchsynergypress.com/index.php/ijmesh

International Journal of Management, Entrepreneurship, Social Science and Humanities

(IJMESH)

ISSN 2580-0981 (online)

Volume 4 Issue 1 (2021): 17-31

\title{
Factors Affecting Academic Self-Efficacy and Its impact on Perceived Academic Burnout among Students in Bangladesh.
}

\author{
Sraboni Akter ${ }^{1}$ \\ ${ }^{1}$ Khulna University, Bangladesh
}

\begin{abstract}
Burnout is a common phenomenon in everyone lifes, but students have the most adverse effect on self-efficay as a result of burnout. This present research aims to examine the factors related to academic self-efficacy and to identify the relationship between academic self-efficacy and academic burnout in Khulna city, Bangladesh.Besides that, providing some solutions regarding resolving this issues. For this present study data was collected via both E-mail and self-administrative questionnaire from 272 university students. We use descriptive and inferential method. From the research findings and analysis, and all the variables explaining significaane value of 0.00 which is are statistically significant, also there is a statistically significant relationship between Academic selfefficacy and Academic Burnout.
\end{abstract}

Keywords: Academic performance, Academic stress, Academic support

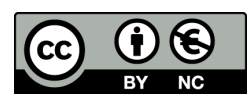

This is an open access article under the CC-BY-NC license

\section{INTRODUCTION}

University life is a significant period in every young adult's life because of many new experiences, trials, life events, freedom and gain important life skills such as problem-solving, time management, and on top of all, to get a degree for a happier future. For some, the university life may be a positive change but undoubtedly it is full of self-doubt, stress, anxiety, and burnout. Here students burnout refers a state of emotional, physical, and mental fatigue triggered by academic pressure like desire of high results ,lack of teachers support and lack of facilities and many more.In the view of Schwarzerand Hallum (2008) burnout is emotional exhaustion and pessimism that is often experienced by people for various reasons and also added that people with higher self-efficacy are more positive when faced with challenges. Fives et al., (2007) also asserted that ,this is especially true for students where they have to cope up with everyday tasks, teacher's expectations, family expectations, personal achievement, and many more. Self-efficacy is a guarantee one feels about certain actions which affect his level of personal efforts and performance as a form of motivation. self-efficacy scholars have explored three areas as efficacy beliefs and career preferences (Lent and Hackett, 1987), instructional practices and student results (Ashton and Webb, 1986), and finally academic performances and achievements (Multon et al., 1991). Skaalvik and Skaalvik (2007) supported that all these expectations make a question mark on the student's self-efficacy and their perceived burnout criteria. Although there is a various reason behind low self-efficacy and burnout this study only focusses on academic self-efficacy and burnout factors.

Corresponding author:

sraboniakterhrm@gmail.com

DOI: https://doi.org/10.31098/ijmesh.v4i1.494

Research Synergy Foundation 
According to ,Maslach, \& Leiter , (2016) described that most of the researchers only provide focus on occupational burnout but in recent times most of the researchers are now trying to put the focus on student's mental health .This study also supported by Federici \& Skaalvik, (2012) identified the main reason behind the burnout is low self-efficacy. Hence, our study supported by (kim , 2020; Shakeel et al.,2021) about self-efficacy and perceived burnout. Most of the researchers have seen self-efficacy as a factor of burnout but they completely ignore the academic factors that can enhance self-efficacy. Hence, we try to fill this significant gap as the first objective: we want to identify the factors and their relationship with academic self-efficacy. The second objective although quite similar to other researchers is that to show the relationship between academic factors and burnout but for this present study, only three criteria have been chosen that are: academic performance, academic stress, and academic support. Furthermore, whenever they talked about academic burnount and its relationto self-efficacy they mainly focus on teachers rather than students Friedman, I. A., (2003). The final aim is to investigate is there any relationship between academic self-efficacy and academic burnout, based on Conservation of Resource Theory (COR) and Social Cognitive Theory (SCT). Finally ,by observing these relationship this study will propose some recommendations to cope up with the problems.

\section{LITERATURE REVIEW}

Burnout is a state of emotional, physical, and mental fatigue triggered by extreme and continued stress not to be able to meet constant demands which are caused by negative emotions towards home, work, and social life which is supported by Conservation of Resource Theory (COR) for understanding the reasons behind stressful circumstances and response situations (Hobfoll et al., 2000). Burnout mostly causes psychological agony such as anxiety, depression, frustration, hostility, fear, and so on. The former investigation of(Choi et al., 2014) had visible example such as lower commitment, higher turnover, absenteeism, reduced productivity, low morale, and lower human deliberation, and many more problems Occupation burnout is the more common negative side of a system based on stress and constrained in their working situation and eventually, they feel uninterested and disheartened.Although Occupation burnout is the most visible type of conflict many signals exist to support the existence of burnout in college students (Yang \& Farn 2005) and this present study is about the student's burnout. Mostly student burnout is a concept related to illbeing as it is related with academic work (Silva et al.2017). Student burnout is defined as a mixture of fatigue at schoolwork, cynicism towards the meaning of school, and a sense of inadequacy as a student and (Wang et al., 2015) mentioned that it can be triggered by inconsistencies between student's internal resources, task workload, fear of academic success and expectations of school results, self-efficacy and so on.

In social cognitive theory, Bandura (1977) describes self-efficacy as a future-oriented trust to utilize individual competencies, skills, and abilities motivation and get the results. Self-efficacy credence has attained increasing attention in educational research especially for academic inspiration. Multon et al., (1991) recognized three major types of experiences related to self-efficacy efficacy beliefs, firstly choice behavior of people to occupy in tasks by being confident or avoidance, secondly the degree to effort expenditure and persistence through the higher sense of self-efficacy, and finally emotional reactions such as stress and burnout. Besides, various studies revealed that self-efficacy depends on various factors like age, gender, locus of control, autonomy and 
independence, need for achievement, family or social support, previous experiences, and many more.For measuring student self-efficacy (Bandura ,1977) model is used, by some typical questions such as their perception towards solving study related problems, contribution in classes ,confidence level and many more. Jamali et al.,(2013) proven that studentself-efficay has a positive relation with academic burnout.

Burnout is related in every aspect of our life, which sometimes positively or negatively related with self-effcacy. Although some researchers have modelled self-efficacy and the dimensions of burnout to be concurrently associated (Skaalvik \& Skaalvik, 2010), other researchers have attributed low self-efficay levels as the root cause of burnout (Cherniss, 2017). Shoji et al., (2016) used a meta-analysis which reported that across occupations, self-efficacy was negatively associated with job burnout .Many research is mainly confined to those factors that affect student's self-efficacy (SSE) like participation, teacher and administration support, academic performance, academic achievement, academic stress, level of understanding, flexibility, attitude to learning new ideas, sharing ideas environment, and so on. All the factors doesn't contribute similarly among students. Among all the factors , academic factors are more crucial for a developing countries like our, for this study Academic achievement (Sullivan, 2010), academic stress (Gadzella \& Masten,2005), and academic support (Russell et al., 1987) have been used to measure burnout. In my opinion if the authority will be able to find a solutions regarding this particular factors and can develop a medium to lessen this it be mutually benefited for both students and teachers.

\section{Academic achievement}

Academic achievement has been one of the most pivotal points for educationalists and researchers for decades because problems in the performance and achievement in student's academic career predict dropout of a student and most of the previous academic achievement research has balanced on the psychological mechanism, self-efficacy (Mitchell et al., 1994). Yang et al., (2005) described that to build interaction between many variables, such as subject's characteristics, cognitive and personality traits, self-perceptions are related to academic achievement. Research has proven by Meta-analyses of school results on achievement outcomes (Bremberg, 2006). School effect is around $8 \%$ and the classroom effect begins at $16 \%$ and spreads $60 \%$. In Finland, the school-level effect is one of the lowest among the OECD countries. Besides that, when students perceive that they are in a translucent, just, and fair atmosphere, they achieve better academic performance as a result of the display greater emotional steadiness. However, if students perceive that they are treated unethically, with disrespect as a result they hate school and avoid going to class, which causes lower academic performance and emotional depression (Li \& Lerner,2011). Hence, it is easy to understand that the students perceive that they are treated fairly, they have lower burnout and better academic achievement and If the situation is opposite, they have higher burnout and poor academic accomplishment.

\section{Academic Stress}

Jobload is a vital feature to explain the burnout phenomenon (Lubbadeh,2020) not only valid to the employee but also this concept was useful to the student's learning environment. Whenever students determine course overload, tension, failure, lower satisfaction, and lower academic performance. Course load is the most common reason behind this and it happens when students face a problem because of limited time, unsolved problems, and task overload . Yang, (2004) said that most previous research linked with the influence of assignment and burnout indicates a

(C) 2021 International Journal of Management, Entrepreneurship, Social Science and Humanities (IJMESH) ISSN 2580-0981 (online) 
positive link also revealed that course load is the biggest aspect of student pressure. If students perceived a substantial course load, they would have a high burnout rate and low academic achievement. For instance, Öztürk (2019) came up with the results that showed faculty member with a heavy course load and no course load are meaningfully distinctive. Besides, course load was significant in forecasting of emotional exhaustion, and the main assumption on course load has a relationship with burnout.

\section{Academic Support}

Communal support has been recognized as a supply that allows peoples to cope with stress (Russell et al., 1987). Support from co-workers and supervisors has frequently been identified as a defensive mechanism and a medicine against burnout (Cherniss, 1993). McNeill et al., (2018) suggested that the use of autonomy-supportive methods by using teachers and faculty administrators has been linked to academic achievement. Hobfoll et al., (2000) also provided indication that peer support also contributes to students' achievement besides that, Flett, et al., (2019) exposed that students who had been excluded by their peers had lower academic success rates. Prior research recommended that growing teachers' care might be a useful strategy for avoiding student burnout (Russell et al., 1987). Lau et al., (2005) also keen out that burned-out teachers and students may affect each other, lessening satisfaction because students may have the same feelings and expectations of burnout (Lau et al., 2005). Nevertheless, no empirical proposal about the impact of social support on burnout among technical-vocational students was found.

\section{Research model and Hypothesis development}

Burnout has been a prevalent topic of study in psychology and related disciplines for a very long time because it is now not only confined to the employees only. In recent times many researchers have been shown that students face a great deal of burnout because of various academic reasons besides that those factors are inextricably related to student's self-efficacy.

Academic achievement is the focal point for the educational institution because of problems in the and offending behaviors (Uludag, \& Yaratan,2013). Frentz et al. (1991) in their research also showed that pupils who had lower academic achievement associated with emotionally fatigued, used up, irritable, frustrated, or even worn out and hence have lower academic performance. So clearly it is understood that Academic performance is positively related with academic burnout yet some research showed that there is a negative relationship between student burnout and academic achievement. So now it is not unwise to say academic performance is related to academic burnout.

H1: Academic Performance is positively related to Academic Burnout.

Academic achievement is inclined by a multitude of factors such as attitude to the need for achievement (Christidou, V.,2011), and aptitude for successful performance (Schunk, 1991). Academic performance is a consequence of academic competence and motivation (Bandura, 1997). Based on various discoveries from past decades, Bandura (1997) mentioned that gender and academic performance to some extent hinge on on an individual's self-efficacy opinions. Besides that, abundant studies have found that self-efficacy is one of the effects on both general academic achievement and academic performance. Although Pajares (2006) has disparaged several selfefficacy studies that failed to find a connection to academic performance because of not having specific in the dimension of self-efficacy and its related outcome. So, based on this literature the second hypothesis is

H2: Academic performance is positively related to Academic self-efficacy. 
Assignment has been always a major source of burnout in the job which has been proven by most scholars. The situation is also quite similar to the students. As soon as they face more academic stress due to course load most often more or fewer people face burnout. Once students face course overload, they experience tension, a sense of failure, lower satisfaction, which leads to even lower academic performance. Most previous research indicates a positive correlation between workload and burnout. Moreover, previous studies also found that course load is the main factor of student stress (yang,2004). Hence, it can be said that If students perceived a heavy course load, they would have a high burnout rate. Thus, hypothesis can be proposed that:

H3: Academic stress has a positive relationship with Academic burnout.

As it has been proven by various research about the relationship between student burnout and academic stress. Some of the research also indicates that academic stress ultimately disturbs academic self-efficacy in the students. University students are certainly bound to go through stress during their educational career for various reasons like homework, exams, work, clubs, volunteer positions, extra-curricular activities, and so on. Cohen et al., (1983) used Perceived Stress Scale and found that found good internal consistency reliability and test-retest reliability three samples.Further, Cohen and colleagues (1983) found significant predictive and concurrent validity in terms of the PSS among the students. Thus, hypothesis can be proposed that:

H4: Academic stress has a positive relationship with academic self-efficacy.

A significant degree of teacher worth depends on how much students believe their teacher supports them. Teacher support is supposed to teachers for assistance, which is associated with academic interest and psychosocial adjustment and most of the Teacher support is further divided into two constructs such as academic support and personal support (Kim et al.,2018). An important element of providing students' academic support is to be productive and assist with students' development of concepts that seem conceptually similar to potentials of efficiency and organization within Big Five's domain of meticulousness and meta-analysis, suggest that teacher friendliness should be the personality domain most positively associated with teacher personal support, and academic burnout. So, based on this theory hypothesis is,

H5: Academic support has a positive relationship with Academic burnout.

Besides that, Guay et al., (2013) indicated that the use of autonomy-supportive methods by teachers and school administrators has been associated with academic achievement thus led to self-efficacy. Hymel et al. (2001) also presented sign that peer support may also contribute to pupil's achievement because it has a profound influence on their day-to-day behavior and self-efficacy. Guay et al., (2013) in their research also showed that pupils who were rejected by their peers had lower academic achievement and has a lower self-efficacy. Thus, hypothesis can be proposed that,

H6: Academic support has a positive relationship with academic self-efficacy.

Based on the theory of self-efficacy and the previous research it is easy to understand that the greater the self-efficacy, the lower the burnout. High self-efficacy supports generating feelings of calmness for tough tasks and activities. Contrarywise, low self-efficacy might create a belief that raises stress, depression, and a thin vision about problems.Cherniss, (1992)described the relationship between burnout and physiological states, and many previous researchers demonstrated the relationships between self-efficacy and burnout. These results are corresponding with research literature and Bandura's self-efficacy theory which has explained those who do not have self-efficacy, become easily burnout . In short, self-efficacy beliefs affect individuals' selection, 
International Journal of Management, Entrepreneurship, Social Science and Humanities (IJMESH), Vol. 4 (1), 17-31 Factors Affecting Academic Self-Efficacy and Its impact on perceived Academic Burnout among Students in Bangladesh.

Sraboni Akter

purposes, emotional reactions, effort, adjustment, and resistance, and those who have high selfefficacy help create stillness when facing hard assignments and activities. Quite the opposite, low self-efficacy leads to stress, depression, and weak problem-solving. Hence, the hypothesis is

H7: Academic self-efficacy has a positive relationship with academic burnout.

Based on the analysis of previous works and hypotheses, for this present study, some moderating effects can be set. So, for this present study based on the hypothesis the conceptual model is given below:

\section{Conceptual model(fiqure 1)}

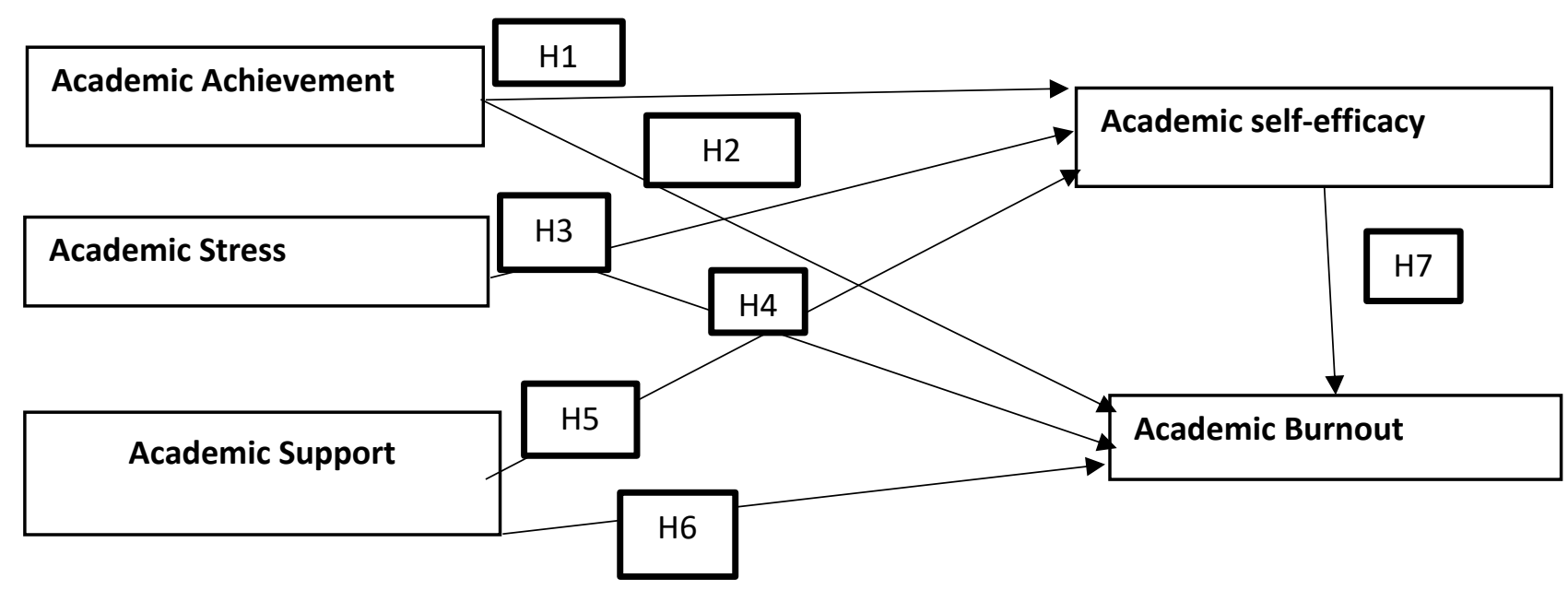

\section{METHODOLOGY}

The target samples for this study were students from four different university both from public and private university in Khulna city Bangladesh. Totally, 4 public and private universities were selected. For data collection 272 questionnaire had been distributed via E-mail and selfadministration. Sample Size has been taken by the help of this equation, where $\mathrm{N}=$ population size, $\mathrm{z}=\mathrm{z}$-score, $\mathrm{e}=$ margin of error $\mathrm{p}=$ standard of deviation

$\mathrm{n}=[\mathrm{z} 2 * \mathrm{p}(1-\mathrm{p})] / \mathrm{e} 2 / 1+[\mathrm{z} 2 * \mathrm{p}(1-\mathrm{p})] / \mathrm{e} 2 * \mathrm{~N}]$

$=[1.652 * 0.5(1-0.5)] /(0.05) 2 / 1+[1.652 * 0.5(1-0.5)] /(0.05) 2 * 1,80,784]$

$=272.24 / 1.0015$

$=271.8$ or 272

Sample size is considered 272 for this survey.

Scales were obligatory for each of the concepts in the research model and from the review of the literature was undertaken to identify construct descriptions validated tools were adapted slightly to fit the present research. For this present study, A close-ended questionnaire with 25 statements was used for this survey. The questionnaire had two sections. In section, A the demographic profile of the respondents was mentioned and section $B$ had questions regarding the construct. For this questionnaire 5-point, Likert scale was used. Here SD= Strongly Disagree, MD = Moderately Disagree, $\mathrm{N}=$ Neutral, MA= Moderately Agree, SA= Strongly Agree. Of the272 students $78 \%$ of the participants 20\% were from Khulna University of Engineering and Technology, the majority which is $38 \%$ were from Khulna University, $23 \%$ from Northern University of Business and 
Technology and the rest are from North Western University. The useable samples included 161 male students and 111 female students. As data were collected from both undergraduate and postgraduate students the amount is $77 \%$ and $23 \%$ respectively. Age also varies among the respondents $21 \%$ age of the respondents between $18-20$ and, 38\% age of the respondents between $21-23,29 \%$ age of the respondents between $24-26$ and rest between $27-29$. Finally, $83 \%$ have accepted that they are suffering from burnout while $17 \%$ denied it. For the current sample, the reliability analysis using Cronbach's coefficient alpha was a quite acceptable overall academic performance $(\alpha=.81)$, academic stress $(\alpha=.89)$ academic support $(\alpha=.61)$, academic self-efficacy $(\alpha=.83)$, and academic burnout $(\alpha=.78)$. Statistical methods used for the analysis included correlation and linear regression analysis. Regression was used to test the relationship between student burnout and academic achievement.

\section{FINDINGS AND DISCUSSION}

Academic performance was measured by the total average score at the end of the semester of students and This study adopted the definition of Brown et al. (1989) and this present study (mean=2.7007 and $\mathrm{SD}=.82292$ ). Academic stress had been adopted from (Ahern \& Norris, 2011) which denoted that when an individual has a feeling of uneasiness regarding academic pressure like course load. For this present study (mean=3.0566 and $\mathrm{SD}=1.01423$ ). Many researchers had been proven that academic support is very much needed for a student and it can become from peers, teachers, and administration and for this study (mean=3.2118 and SD=.98138). Student selfefficacy (Bandura,1977) is an inextricable trait related to all although it can be high and low and this present study found that (mean=2.9441 and $\mathrm{SD}=.88770$ ). Every person in their life more or less faces burnout (Maslach, 1986) and most of the students in their academic life face a great amount of burnout due to academic reason and this present study showed (mean=2.9559 and SD=.98646).

Table 1. Correlation of Aacademic Performance,Academic Stress ,Academic Support And Academic Burnout

\begin{tabular}{|l|l|l|l|l|}
\hline Variables & $\begin{array}{l}\text { Academic } \\
\text { Performance }\end{array}$ & $\begin{array}{l}\text { Academic } \\
\text { stress }\end{array}$ & $\begin{array}{l}\text { Academic } \\
\text { Support }\end{array}$ & $\begin{array}{l}\text { Academic } \\
\text { Burnout }\end{array}$ \\
\hline Academic Performance & 1 & & & \\
\hline Academic stress & $.729^{* *}$ & 1 & & \\
\hline Academic Support & $.460^{* *}$ & $.484^{* *}$ & 1 & 1 \\
\hline Academic Burnout & $.500^{* *}$ & $.532^{* *}$ & $.467^{* *}$ & \\
\hline
\end{tabular}

**. Correlation is significant at the 0.01 level (2-tailed).

*. Correlation is significant at the 0.05 level (2-tailed).

Pearson product-moment correlation coefficient (Table 1) measured the positive relationship between academic performance, academic stress, academic support, and academic burnout. 
International Journal of Management, Entrepreneurship, Social Science and Humanities (IJMESH), Vol. 4 (1), 17-31 Factors Affecting Academic Self-Efficacy and Its impact on perceived Academic Burnout among Students in Bangladesh.

Sraboni Akter

Table 2. Correlation of Academic Performance,Academic Stress ,Academic Support And Academic Self-Efficacy

\begin{tabular}{|l|l|l|l|l|}
\hline Variables & $\begin{array}{l}\text { Academic } \\
\text { Performance }\end{array}$ & $\begin{array}{l}\text { Academic } \\
\text { stress }\end{array}$ & $\begin{array}{l}\text { Academic } \\
\text { Support }\end{array}$ & $\begin{array}{l}\text { Academic self- } \\
\text { efficacy }\end{array}$ \\
\hline Academic Performance & 1 & & 1 & \\
\hline Academic stress & $.729^{* *}$ & 1 & & \\
\hline Academic Support & $.460^{* *}$ & $.484^{* *}$ & 1 & 1 \\
\hline Academic self-efficacy & $.508^{* *}$ & $.509^{* *}$ & $.513^{* *}$ & 1 \\
\hline
\end{tabular}

**. Correlation is significant at the 0.01 level (2-tailed).

*. Correlation is significant at the 0.05 level (2-tailed).

Pearson product-moment correlation coefficient (Table 1) measured the positive relationship between academic performance, academic stress, academic support, and academic self-efficacy.

Table 3. Regression Statistics (Academic Performance, Academic Stress Academic Support And Academic Burnout)

\begin{tabular}{|l|c|c|c|c|}
\hline Independent Variables & $\mathrm{B}$ & $\mathrm{SE}$ & $\beta$ & $\mathrm{P}$ \\
\hline Constant & .737 & .193 & & .000 \\
\hline Academic Performance & .218 & .087 & .182 & .013 \\
\hline Academic stress & .271 & .072 & .279 & .000 \\
\hline Academic Support & .249 & .057 & .248 & .000 \\
\hline $\mathrm{R}$ & .596 & & & \\
\hline $\mathrm{R}^{2}$ & .355 & & & \\
\hline F-Statistic & 49.161 & & & \\
\hline Adj. R ${ }^{2}$ & .348 & & & \\
\hline$N$ & 272 & & & \\
\hline
\end{tabular}

Notes: ${ }^{*} \mathrm{P}<0.05 ;{ }^{* *} \mathrm{P}<0.01$

Dependent Variable: Academic Burnout.

Predictors: (Constant): Academic Performance, Academic stress, and Academic Support.

As a result, multiple regression analysis (Table 3) was also conducted where the three predictors are Academic Performance, Academic stress, and Academic Support. Academic Performance, Academic stress, and Academic Support were independent variables, and Academic Burnout was the dependent variable. From Table 3, it was observed that the coefficient of determination $\left(\mathrm{R}^{2}\right)$ was .355 an indication that there was a variation of $35.5 \%$ on Academic Burnout due to changes in Academic Performance, Academic stress, and Academic Support at a $95 \%$ confidence interval. This showed that $35.5 \%$ of changes in Academic Burnout can be explained based on these predictors and there has a significant relationship within the predictors. The overall model was reasonably fit with the F statistics of 49.161and $\mathrm{P}<0.01$.

Table 4. Regression Statistics (Academic Performance, Academic Stress 
International Journal of Management, Entrepreneurship, Social Science and Humanities (IJMESH), Vol. 4 (1), 17-31 Factors Affecting Academic Self-Efficacy and Its impact on perceived Academic Burnout among Students in Bangladesh.

Sraboni Akter

\begin{tabular}{|c|c|c|c|c|}
\hline \multicolumn{5}{|c|}{ Academic Support And Academic Self-Efficacy) } \\
\hline Independent Variables & B & SE & $\beta$ & $\mathrm{P}$ \\
\hline Constant & .859 & .171 & & .000 \\
\hline Academic Performance & .236 & .077 & .219 & .003 \\
\hline Academic stress & .171 & .064 & .196 & .008 \\
\hline Academic Support & .288 & .051 & .318 & .000 \\
\hline $\mathrm{R}$ & .612 & & & \\
\hline $\mathrm{R}^{2}$ & .374 & & & \\
\hline F-Statistic & 53.407 & & & \\
\hline Adj. $\mathrm{R}^{2}$ & .367 & & & \\
\hline$N$ & 272 & & & \\
\hline
\end{tabular}

Notes: ${ }^{*} \mathrm{P}<0.05 ;{ }^{* *} \mathrm{P}<0.01$

Dependent Variable: Academic self-efficacy.

Predictors: (Constant): Academic Performance, Academic stress, and Academic Support.

As a result, multiple regression analysis (Table 4) was also conducted where the three predictors are Academic Performance, Academic stress, and Academic Support. Academic Performance, Academic stress, and Academic Support were independent variables, and Academic self-efficacy as the dependent variable. From Table 3, it was observed that the coefficient of determination $\left(\mathrm{R}^{2}\right)$ was .374 an indication that there was a variation of $37.4 \%$ on Academic selfefficacy due to changes in Academic Performance, Academic stress, and Academic Support at 95\% confidence interval. This showed that $37.4 \%$ of changes in Academic Burnout can be explained based on these predictors and there has a significant relationship within the predictors. The overall model was reasonably fit with the F statistics of 53.407 and $\mathrm{P}<0.01$.

Table 4. Regression Statistics (Academic Self-Efficacy And Academic Burnout)

\begin{tabular}{|l|c|c|c|c|}
\hline $\begin{array}{l}\text { Independent } \\
\text { Variables }\end{array}$ & B & SE & $\beta$ & P \\
\hline Constant & 1.450 & .141 & & .000 \\
\hline Academic Burnout & .506 & .045 & .562 & .000 \\
\hline $\mathrm{R}$ & .562 & & & \\
\hline $\mathrm{R}^{2}$ & .316 & & & \\
\hline F-Statistic & 124.542 & & & \\
\hline Adj. ${ }^{2}$ & .313 & & & \\
\hline$N$ & 272 & & & \\
\hline
\end{tabular}

Notes: ${ }^{*} \mathrm{P}<0.05 ;{ }^{* *} \mathrm{P}<0.01$

Dependent Variable: Academic Self-efficacy

Predictors: (Constant): Academic Burnout

As a result, multiple regression analysis (Table 5) was also conducted where the one predictor is Academic Self-efficacy. Academic Self-efficacy was independent variable and Academic

(C) 2021 International Journal of Management, Entrepreneurship, Social Science and Humanities (IJMESH)

ISSN 2580-0981 (online) 
Burnout as the dependent variable. From Table 3, it was observed that the coefficient of determination $\left(\mathrm{R}^{2}\right)$ was .316 an indication that there was a variation of $31.6 \%$ on Academic Burnout due to changes in Academic Self-efficacy at 95\% confidence interval. This showed that $31.6 \%$ of changes in Academic Burnout can be explained based on these predictors and there has a significant relationship within the predictors. The overall model was reasonably fit with the F statistics of 124.542 and $\mathrm{P}<0.01$.

Three research objectives were used at the outset of this study: (1) to examine the relationship of the factors with academic burnout meanwhile, (2) this research also attempts to examine the factors related to academic self-efficacy, and Finally, (3) does academic self-efficacy significantly affect academic burnout. For achieving those aims correlation and regression analysis had been used to validate the hypothesis.

Hypothesis 1: Academic Performance is positively related to Academic Burnout.

In these results, the correlation between Academic Performance and Academic Burnout is ( $\mathrm{r}$ $=, .500^{* *}(\mathrm{P}<0: 01)$ which indicates that there is a moderate positive relationship between the variables. the relationship was significant $(\beta=.218$, Sig. $=0.013)$ as the Sig. the value was less than .05. This result suggested that Academic Performance and Academic Burnout have a positive relationship which validates $\mathrm{H} 1$.

Hypothesis 2: Academic performance is positively related to Academic self-efficacy.

In these results, the correlation between Academic Performance and Academic self-efficacy is $\left(\mathrm{r}=, .508^{* *}\right)(\mathrm{P}<0: 01)$ which indicates that there is a moderate positive relationship between the variables. the relationship was significant $(\beta=.236$, Sig. $=0.003)$ as the Sig. the value was less than .05. This result suggested that Academic Performance and Academic self-efficacy have a positive relationship which validates $\mathrm{H} 2$.

As presented in Tables 3 and 4, showed positive relationship for both Academic Performance and Academic Burnout and Academic Performance and Academic self-efficacy which also proven by Previous studies (Cheng \& McCarthy, 2018) and (Mitchell et al., 1994) respectively Although Pajares (2006) denied.

Hypothesis 3: Academic stress has a positive relationship with Academic burnout.

In these results, the correlation between Academic stress and Academic Burnout is $(r=$, $\left..532^{* *}\right)(\mathrm{P}<0: 01)$ which indicates that there is a moderate positive relationship between the variables. the relationship was significant $(\beta=.271$, Sig. $=0.000)$ as the Sig. the value was less than .05. This result suggested that Academic Performance and Academic Burnout have a positive relationship which validates $\mathrm{H} 3$.

Hypothesis 4: Academic stress has a positive relationship with Academic self-efficacy.

In these results, the correlation between Academic stress and Academic self-efficacy is $(\mathrm{r}=$, $\left..509^{* *}\right)(\mathrm{P}<0: 01)$ which indicates that there is a moderate positive relationship between the variables. the relationship was significant $(\beta=.171$, Sig. $=0.008)$ as the Sig. the value was less than .05. This result suggested that Academic stress and Academic self-efficacy have a positive relationship which validates $\mathrm{H} 4$.

As presented in Tables 3 and 4, showed positive relationship for both Academic stress and Academic Burnout and Academic stress and Academic self-efficacy which also proven by Previous studies Cohen et al., (1983) and (Yeaman, J.,1994). 
Hypothesis 5: Academic support has a positive relationship with Academic Burnout.

In these results, the correlation between Academic support and Academic Burnout is $(r=$, $.467^{* *}(\mathrm{P}<0: 01)$ which indicates that there is a moderate positive relationship between the variables. the relationship was significant $(\beta=.249$, Sig. $=0.000)$ as the Sig. the value was less than .05. This result suggested that Academic support and Academic Burnout have a positive relationship which validates $\mathrm{H} 5$.

Hypothesis 6: Academic Support has a positive relationship with Academic Self-Efficacy.

In these results, the correlation between Academic support and Academic self-efficacy is $\mathrm{r}$ $\left.=, .513^{* *}\right)(\mathrm{P}<0: 01)$ which indicates that there is a moderate positive relationship between the variables. the relationship was significant $(\beta=.249$, Sig. $=0.000)$ as the Sig. the value was less than .05 . This result suggested that Academic support and Academic self-efficacy have a positive relationship which validates $\mathrm{H} 6$.

As presented in Tables 3 and 4, showed a positive relationship for both Academic support and Academic Burnout and Academic support and Academic self-efficacy which was also proven by Previous studies (Oberle, E., \& Schonert-Reichl,2016) and Chang et al, (2016).

Hypothesis 7: Academic self-efficacy has a positive relationship with Academic Burnout.

In these results, the regression analysis between Academic self-efficacy and Academic Burnout is the relationship was significant $(\beta=.506$, Sig. $=0.00)$ as the Sig. the value was less than .05. This result suggested that Academic self-efficacy and Academic Burnout have a positive relationship which validates $\mathrm{H} 7$.

As presented in 5, Academic self-efficacy and Academic Burnout have a significant positive relationship which is proven by Cherniss, (1992,) who described the relationship between burnout and physiological states, eventually between self-efficacy and burnout.

In the previous research they mostly focus on self-efficay in relation with academic achievement and performance or factors like gender, education level, high or low level of selfefficacy but this study main focus on the factors that affects student self-efficacy and their relationship with bournout. Based on the data analysis here , the significance value shows the goodness of the model. As the significance value is .000 , which indicates that the model used in this study fits with the data because the lower the significance value the better the model fit. All the variables have a positive relationship so it can be concluded that all the hypotheses are validated. For this present study, COR and SCT theory was used to examine the factors related to academic burnout and students self-efficay and the results are also supported by previous research .

\section{CONCLUSION}

The aim of the present study was firstly to examine the factors related to academic burnout meanwhile, secondly, this research also attempts to examine the factors related to academic selfefficacy and Finally, does academic self-efficacy significantly affect academic burnout in Khulna city, Bangladesh. The findings showed that there is a significant relationship between self-efficacy and burnout among three different academic factors such as academic performance, academic stress, and academic support. Besides that, the results also showed a significant relationship between academic self-efficacy and academic burnout. 
However, unlike our study, in their study, no negative correlation was found between academic performance, academic stress, academic support, academic self-efficacy, and academic burnout. From the research findings and analysis, it was found out that all the p-values for all the variables were found to be less than 0.05 , an indication that was statistically significant for some variables. Academic achievement is inclined by a multitude of factors such as attitude to the need for achievement (Christidou, V.,2011), and aptitude for successful performance (Schunk, 1991) and although Pajares (2006) has disparaged several self-efficacy studies that failed to find a connection to academic performance. Kim et al.,(2018) stated that academic support and personal support have a connection on self-efficacy . Various studies such as Aloe et al.,(2014); Skaalvik \& Skaalvik, (2010) found negative association between self-efficacy and job burnout .

This study provides us evidence that students are facing burnout because of academic performance and academic stress more and that's why university teachers should be more flexible towards students so that they can cope up with this academic burnout. Furthermore, the authority should provide some assistance for increasing student's self-efficacy and new methods can be used for making the course more easy and friendly Especially, for the course plan and design and teaching content. This result is dependable with the policy of the Ministry of Education and educational bureaus, which has been actively involved in designing the program to reduce student stress and to improve performance, and also making policies and teaching strategies to increase student learning motivation.

\section{LIMITATION \& FURTHER RESEARCH}

This research does not identify the degree of self-efficacy or burnout level or is there any difference in the demographic unit like age, gender, marital status, level of education, living arrangements and this limitation has a broad aspect for the future research. A general contribution for this study is that it will help to know whether academic factors have any relationship with selfefficacy or not as well as if there is any relationship then whether it is significant or not.

\section{REFERENCES}

Aloe, A. M., Amo, L. C., \& Shanahan, M. E. (2014). Classroom management self-efficacy and burnout: A multivariate meta-analysis. Educational Psychology Review, 26, 101-126.

Bandura, A. (1977). Self-efficacy: toward a unifying theory of behavioral change. Psychological review, 84(2),.191.

Casanova, P. F., García-Linares, M. C., de la Torre, M. J., \& Carpio, M. D. L. V. (2005). Influence of family and socio-demographic variables on students with low academic achievement. Educational psychology, 25(4),423-435.

Chang, E., Lee, A., Byeon, E., Seong, H., \& Lee, S. M. (2016). The mediating effect of motivational types in the relationship between perfectionism and academic burnout. Personality and Individual Differences, 89, 202-210.

Cheng, B. H., \& McCarthy, J. M. (2018). Understanding the dark and bright sides of anxiety: A theory of workplace anxiety. Journal of Applied Psychology, 103(5), 537.

Cherniss, C., (1993). The role of professional self-efficacy in the etiology and amelioration of burnout. In: Schanfeli, W.B., Maslach, C., Marek, T. (Eds.), Professional Burnout: Recent Developments in Theory and Research. Taylor \& Francis, Washington, DC, pp. 115-129.

Choi, S., Cheong, K. K., \& Feinberg, R. A. (2012). Moderating effects of supervisor support, monetary rewards, and career paths on the relationship between job burnout and turnover intentions in the context of call centers. Managing Service Quality: An International Journal. 
Christidou, V. (2011). Interest, Attitudes and Images Related to Science: Combining Students' Voices with the Voices of School Science, Teachers, and Popular Science. International Journal of Environmental and Science Education, 6(2), 141-159.

Cohen, S. (1986). Contrasting the Hassles Scale and the Perceived Stress Scale: Who's really measuring appraised stress?

Cutrona, C. E., \& Russell, D. W. (1987). The provisions of social relationships and adaptation to stress. Advances in personal relationships, 1(1), 37-67.

Federici, R. A., \& Skaalvik, E. M. (2012). Principal self-efficacy: Relations with burnout, job satisfaction and motivation to quit. Social Psychology of Education, 15(3), 295-320.

Fives, H., Hamman, D., \& Olivarez, A. (2007). Does burnout begin with student-teaching? Analyzing efficacy, burnout, and support during the student-teaching semester. Teaching and teacher education, 23(6), 916-934.

Flett, G., Khan, A., \& Su, C. (2019). Mattering and psychological well-being in college and university students: Review and recommendations for campus-based initiatives. International Journal of Mental Health and Addiction, 17(3), 667-680.

Frentz, C., Gresham, F. M., \& Elliott, S. N. (1991). Popular, controversial, neglected, and rejected adolescent: Contrasts of social competence and achievement differences. Journal of School Psychology, 29(2), 109-120.

Friedman, I. A. (2003). Self-efficacy and burnout in teaching: The importance of interpersonalrelations efficacy. Social Psychology of Education, 6(3), 191-215.

Gadzella, B., \& Masten, W. (2005). An analysis of the categories in the student-life stress inventory. American Journal of Psychological Research, 1, 1-10

Guay, F., Ratelle, C., Larose, S., Vallerand, R. J., \& Vitaro, F. (2013). The number of autonomysupportive relationships: Are more relationships better for motivation, perceived competence, and achievement? Contemporary Educational Psychology, 38(4), 375-382.

Hobfoll, S. E., Shirom, A., \& Golembiewski, R. (2000). Conservation of resources theory. Handbook of organizational behavior, 57-81.

Jamali, M., Noroozi, A., \& Tahmasebi, R. (2013). Factors affecting academic self-efficacy and its association with academic achievment among students of Bushehr University Medical Sciences 2012-13. Iranian Journal of Medical Education, 13(8), 629-641.

Kim, L. E., \& Burić, I. (2020). Teacher self-efficacy and burnout: Determining the directions of prediction through an autoregressive cross-lagged panel model. Journal of Educational Psychology, 112(8), 1661.

Lau, P. S., Yuen, M. T., \& Chan, R. M. (2005). Do demographic characteristics make a difference to burnout among Hong Kong secondary school teachers? In Quality-of-life research in Chinese, western and global contexts (pp. 491-516). Springer, Dordrecht.

Leiter, M. P., \& Maslach, C. (2009). Nurse turnover: the mediating role of burnout. Journal of nursing management, 17(3), 331-339.

Lent, R. W., \& Hackett, G. (1987). Career self-efficacy: Empirical status and future directions. Journal of vocational Behavior, 30(3), 347-382.

Lent, R. W., Lopez, F. G., Brown, S. D., \& Gore Jr, P. A. (1996). Latent structure of the sources of mathematics self-efficacy. Journal of Vocational Behavior, 49(3), 292-308.

Li, Y., \& Lerner, R. M. (2011). Trajectories of school engagement during adolescence: implications for grades, depression, delinquency, and substance use. Developmental psychology, 47(1), 233.

Lubbadeh, T. (2020). Job burnout: a general literature review. Int Rev Manag Mark, 10, 7-15.

Maslach, C., \& Leiter, M. P. (2016). Understanding the burnout experience: recent research and its implications for psychiatry. World psychiatry, 15(2), 103-111.

McDougall, P., Hymel, S., Vaillancourt, T., \& Mercer, L. (2001). The consequences of childhood peer rejection. Interpersonal rejection, 213-247.

(c) 2021 International Journal of Management, Entrepreneurship, Social Science and Humanities (IJMESH)

ISSN 2580-0981 (online) 
McNeill, K., Durand-Bush, N., \& Lemyre, P. N. (2018). Thriving, depleted, and at-risk Canadian coaches: Profiles of psychological functioning linked to self-regulation and stress. International Sport Coaching Journal, 5(2), 145-155.

Mitchell, T. R., Hopper, H., Daniels, D., George-Falvy, J., \& James, L. R. (1994). Predicting self-efficacy and performance during skill acquisition. Journal of Applied Psychology, 79(4), 506.

Multon, K. D., Brown, S. D., \& Lent, R. W. (1991). Relation of self-efficacy beliefs to academic outcomes: A meta-analytic investigation. Journal of counseling psychology, 38(1), 30.

Oberle, E., \& Schonert-Reichl, K. A. (2016). Stress contagion in the classroom? The link between classroom teacher burnout and morning cortisol in elementary school students. Social Science \& Medicine, 159, 30-37.

Omolayo, B. O. (2009, August). LEADERSHIP AND SCHOOL IMPROVEMENT IN A CHANGING WORLD OF GLOBALIZATION. In 12TH INTERNATIONAL CONFERENCE (p. 154).

Özdemir, B., \& Demir, A. (2019). Romantic relationship satisfaction, age, course load, satisfaction with income and parental status as predictors of instructors' burnout: Evidence from a correlational study. Current Psychology, 38(5), 1083-1098.

Pajares, F. (2006). Self-efficacy during childhood and adolescence. Self-efficacy beliefs of adolescents, 5, 339-367.

Pajares, F., \& Schunk, D. (2001). The development of academic self-efficacy. Development of achievement motivation. United States, 7, 1-27.

Shakeel, S., Khan, M. M., Khan, R. A. A., \& Mujtaba, B. G. (2021). Linking Personality Traits, SelfEfficacy and Burnout of Teachers in Public Schools: Does School Climate Play a Moderating Role?. Public Organization Review, 1-21.

Schaufeli, W., \& Salanova, M. A. R. I. S. A. (2014). Burnout, boredom and engagement at the workplace.

Schunk, D. H. (1991). Self-efficacy and academic motivation. Educational psychologist, 26(3-4), 207-231.

Schwarzer, R., \& Hallum, S. (2008). Perceived teacher self-efficacy as a predictor of job stress and burnout: Mediation analyses. Applied psychology, 57, 152-171.

Sellström, E., \& Bremberg, S. (2006). Is there a "school effect" on pupil outcomes? A review of multilevel studies. Journal of Epidemiology \& Community Health, 60(2), 149-155.

Silva, M. N., Sánchez-Oliva, D., Brunet, J., Williams, G. C., Teixeira, P. J., \& Palmeira, A. L. (2017). “What goes around comes around": Antecedents, mediators, and consequences of controlling vs. need-supportive motivational strategies used by exercise professionals. Annals of Behavioral Medicine, 51(5), 707-717.

Skaalvik, E. M., \& Skaalvik, S. (2007). Dimensions of teacher self-efficacy and relations with strain factors, perceived collective teacher efficacy, and teacher burnout. Journal of educational psychology, 99(3), 611.

Shoji, K., Cieslak, R., Smoktunowicz, E., Rogala, A., Benight, C. C., \& Luszczynska, A.(2016). Associations between job burnout and self-efficacy: A meta-analysis. Anxiety, Stress, and Coping, 29, 367-386.

Uludag, O., \& Yaratan, H. (2013). The effects of justice and burnout on achievement: An empirical investigation of university students. Croatian Journal of Education: Hrvatski časopis za odgoj i obrazovanje, 15(Sp. Ed. 2), 97-116.

Wang, C. W., \& Neihart, M. (2015). Academic self-concept and academic self-efficacy: Self-beliefs enable academic achievement of twice-exceptional students. Roeper Review, 37(2), 63-73.

Webb, R. B., \& Ashton, P. T. (1986). Teacher motivation and the conditions of teaching: A call for ecological reform. Journal of Thought, 43-60.

Yang, H. J. (2004). Factors affecting student burnout and academic achievement in multiple enrollment programs in Taiwan's technical-vocational colleges. International journal of educational development, 24(3), 283-301. 
International Journal of Management, Entrepreneurship, Social Science and Humanities (IJMESH), Vol. 4 (1), 17-31 Factors Affecting Academic Self-Efficacy and Its impact on perceived Academic Burnout among Students in Bangladesh.

Sraboni Akter

Yang, H. J., \& Farn, C. K. (2005). An investigation the factors affecting MIS student burnout in technical-vocational college. Computers in human behavior, 21(6), 917-932.

Yeaman, J. (1994). College Student Stress: Who Is Resilient? Who Is Vulnerable? (Doctoral dissertation). 